\title{
Increasing the international visibility of the Brazilian Journal of Geology
}

\author{
Aumentando a visibilidade \\ internacional da Brazilian Journal of Geology
}

Since January 1 ${ }^{\text {st }}$,2017, the Board of Directors of the Brazilian Geological Society has honored the signatories to assume the editorial activities of the Brazilian Journal of Geology (BJG). Our responsibility is tremendous in the face of the hard work and efforts made by the previous Editor-in-Chief, Prof. Umberto G. Cordani, who was in charge of the journal for a little more than five years and, in this short term, gave it a new format, increased the publication of articles in English, and attained indexation in the best international databases such as Scopus and Web of Science. In 2015, the BJG received its first Impact Factor of 0.6, twice as expected.

Prof. Cordani also set up a network of internationally renowned Geoscientists who acted rigorously and efficiently as Associated or Area Editors. The high standards applied by this group of editors has certainly increased the quality of the articles and contributed decisively to a greater international visibility of the BJG. Cordani remains as an Associated Editor of the BJG and we will certainly seek his help. We want to express our deep recognition to the work performed by Prof. Cordani. Your efforts are truly appreciated.

From now on the new editors have the challenge to continue and improve the editorial work, increase the journal international visibility and consequently its Impact Factor. The commitment of the editorial board will be decisive in this regard.

For 2017, the new editors aim to implement an early view system, so articles approved for publication will be immediately available in the BJG homepage. With the secretariat support of the Brazilian Geological Society, a DOI identifier is being attributed to all previous articles of the BJG and its precursor, the Brazilian Journal of Geosciences (Revista Brasileira de Geociências). This ensures an effective and widespread diffusion of the excellent collection of articles published in almost 50 years.

Certainly, the authors play the main role to consolidate the BJG as their primary vehicle for the publication of high-level scientific papers in the Geosciences, whether in Brazil or in the neighboring continental and oceanic regions. We invite the Geoscientific community to choose the BJG for the dissemination of their work.

Claudio Riccomini Editor-in-Chief Carlos Henrique Grohmann Adjunct-Editor 